\title{
Safety of Mining Engineering Buildings and Facilities Under Fem Analysis and Catastrophe Theory
}

\author{
Pershin Vladimir Viktorovich, Nazarov Dmitriy Ivanovich
}

\section{Department of Construction of Underground Facilities and Mines, Mining Institute, T. F. Gorbachev Kuzbas State Technical University, City Kemerovo, 650000, Russia}

\begin{abstract}
The analysis of bearing structures of mining engineering buildings is conducted, the relationship between geometrically nonlinear FEM analysis and catastrophe theory in the dynamic fracture of facilities under static loading is shown.
\end{abstract}

Keywords: FEM, geometrically nonlinear FEM analysis, structure fracture, bifurcation of structure joints, catastrophe theory.

\section{Introduction}

Current economic conditions make demand on the construction of mining engineering buildings and facilities designed with the use of FEM analysis program, Russian - Lira, ScadOffice, foreign - ANSYS, Nastran, etc. Current Russian legislation - Ф3-384 "Regulations on safety of buildings and facilities" requires to follow Standardized Regulations 16.13330.2011 "Steel Construction (updated edition of Construction Rules and Regulations II-23$\left.81^{*}\right)$ " designing steel bearing structures of buildings and facilities of the coal mining industry enterprises.

According to the given regulation it is prescribed to perform the structural analysis taking into account the geometric nonlinearity. However, the necessity of considering the bifurcations in the geometrically nonlinear analysis of building structures is not regulated.

\section{Work characteristic}

The problem of consideration of bifurcations in FEM analysis was formulated in the papers ${ }^{[1,2,3]}$ in the form of test problems, one of them is shown in Fig. 1, the base of the problem is linear elastic rod, i.e. $\square l=N \square l / \mathrm{EA}$, where $\square l$ is - rod extension, $N$ - longitudinal force in the rod, $l$ - length of the rod, EA - the longitudinal stiffness of the rod. The deformation scheme of this structure is shown in Fig. 2.

The example given and test problems ${ }^{[1]}$ show that under the bifurcation the finite element method, solving problems in a static setting, cannot be applied, and the bifurcation leads to the destruction of structures.

Fig. 3, 4 presents schemes and graphs for the analysis of bifurcations.

For the analysis of brittle (dynamic) fracture under static load, we consider the structure shown in Fig. 5.

In accordance with the classical theory of catastrophes ${ }^{[4]}$, an example of the codimension 1 bifurcation is shown in Fig. 6.

However, when modeling the bifurcation taking into consideration the dynamic parameters of the system, namely, for the paired ВСтЗКп steel corner №10, $150 \mathrm{~cm}$ long with a deviation of $7 \mathrm{~cm}$, we obtain the critical force of $\approx 500$ kilogram-force, deflection before bifurcation $-3.172 \mathrm{~cm}$, after bifurcation (point $\mathrm{D}$ in Fig. 6) corresponding to static load $\approx 4500$ kilogram-force. The impact energy under bifurcation $\approx 100$ joule $/ \mathrm{cm}^{2}$, which exceeds the impact energy absorbed by the steel $\approx 100$ joule $/ \mathrm{cm}^{2}$. 
The more comprehensive energy analysis of the singleton bifurcation may show that the static equilibrium points of the system (Newtonian mechanics), the minimum point of the system energy
(Chaplygin mechanics) and the variation point of the system energy (Lagrangian mechanics) - do not match, which indirectly indicates the nonholonomic properties of the system.

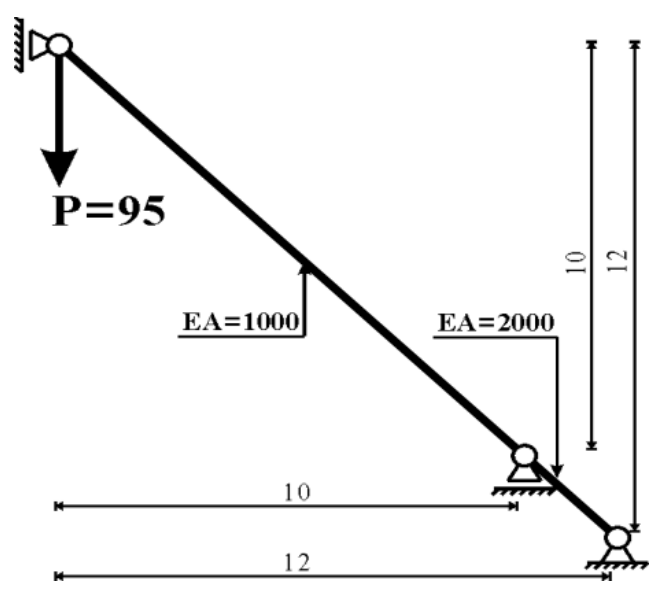

Fig. 1: Scheme of the structure

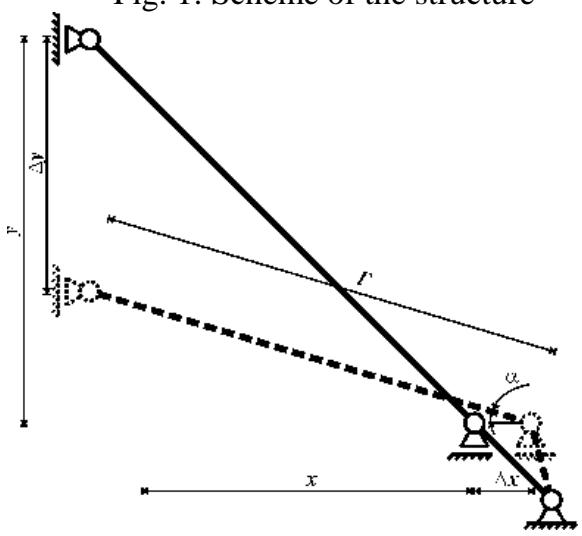

Fig. 3:Scheme of interaction between left and right elements

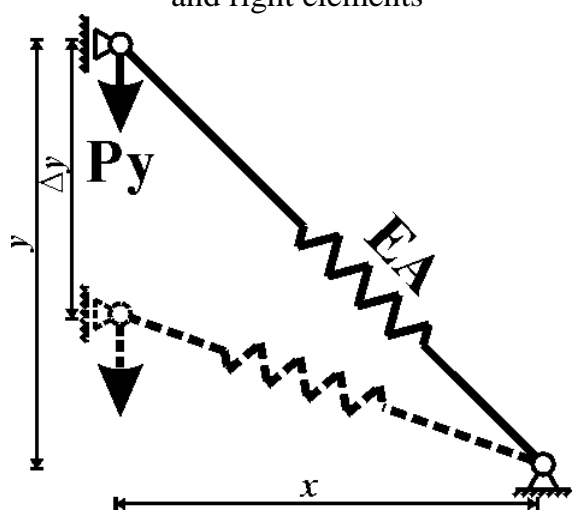

Fig. 5: Scheme of the element bifurcation model

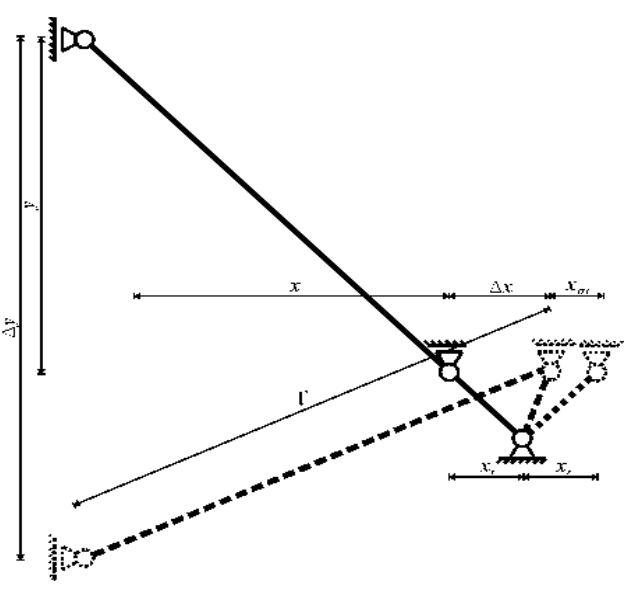

Fig. 2:Deformed scheme

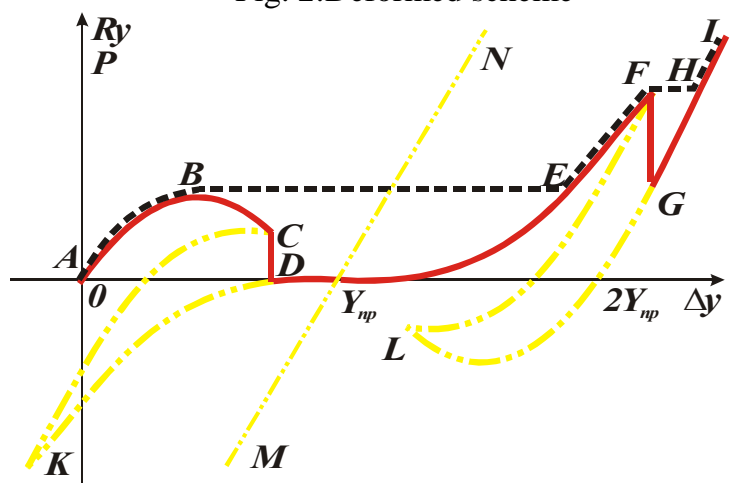

Fig. 4:Determination of critical force for the right element position

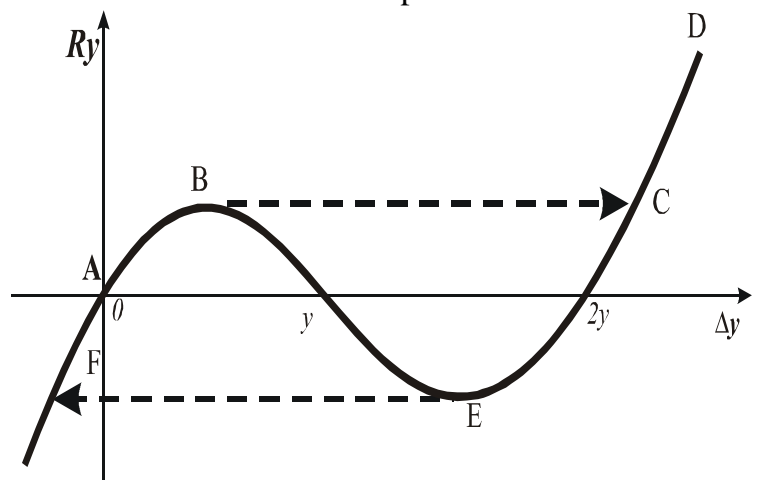

Fig. 6: Position bifurcation according to catastrophe theory 
Graph of external Py force energy changes and the deformation energy is shown in Fig. 7.

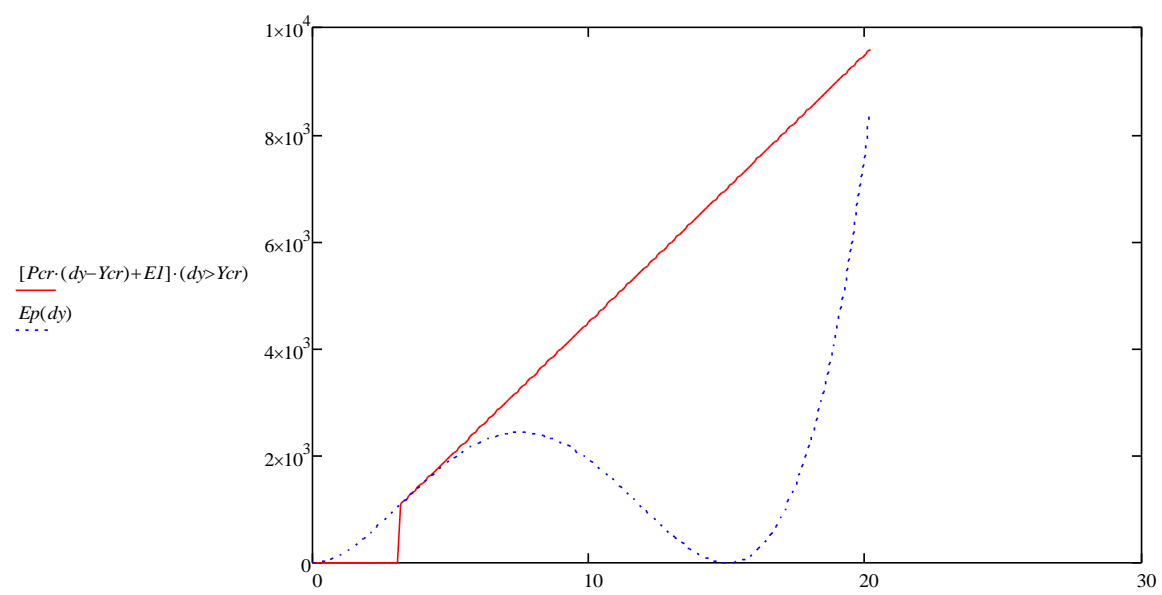

Fig. 7. Graph of external force energy changes and the deformation energy

The building in city Prokopyevsk of Kemerovo region surveyed after its fracture in 2011 by experts of Kuzbas State Technical University and OOO «Kemerovostroyproekt» (LLC "Kemerovo Construction Design") may serve as an example of the structure failure provoked by bifurcation of joints. The aim was to develop guidelines and working documents for the earliest possible repair of the building. However, this work occurred to be significant for science, due to the specific destruction of structures.

The industrial-purpose building, singlestorey, single span, of $18 \times 30 \mathrm{~m}$ size and 8.34m height (see Fig.8).

The building was constructed in 2009 according to the 08/10/2007 design made by the specialized licensed design organization.

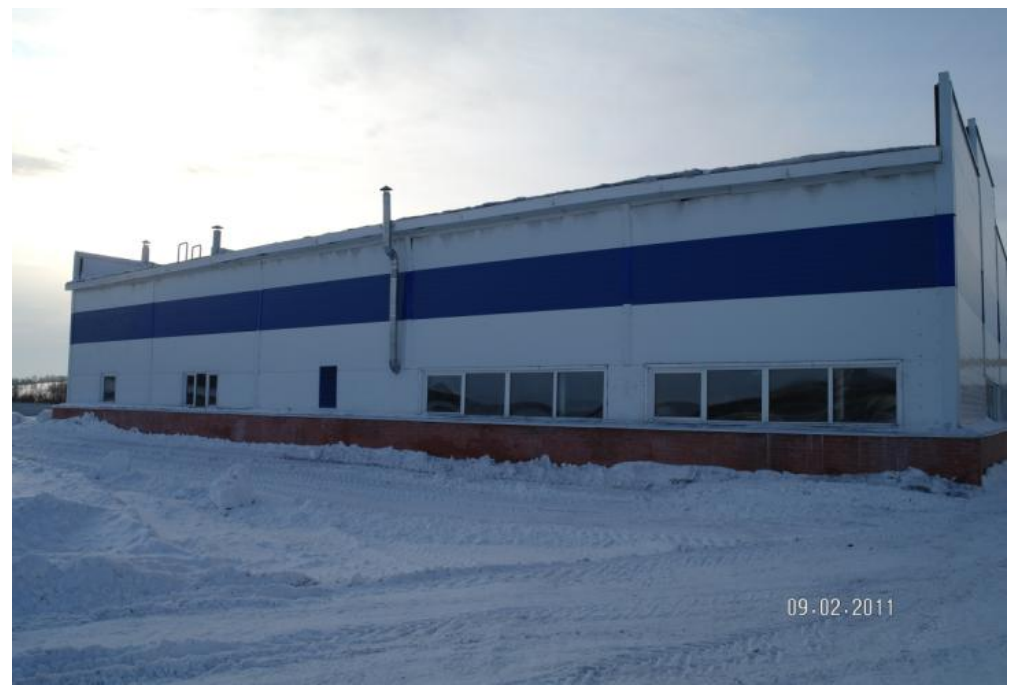

Fig. 8: The general view of the building

Climatic conditions are:

- the normative wind pressure - 30 $\mathrm{kg} / \mathrm{m} 2$ (II district); 
- the designed value of the snow cover weight - $240 \mathrm{~kg} / \mathrm{m} 2$ (IV district);

- the designed temperature of the coldest five days $-39^{\circ} \mathrm{C}$;

- seismic area - 7B.

Exterior walls are from sandwich panels.

Roof bearing structures are $18 \mathrm{~m}$ span gabled metal girders.

Columns - metal.

Foundations - piles with monolithic grillage.

Runs along the upper girders are from rolled profiles.

Chord and column braces are of continuous-type bent steel square profiles.

Roofing is soft of rolled materials.

Roof insulation is mineral wool.

During the examination the causes of fracture of bearing structures were studied. The fracture of the building occurred after one year of use, the building was designed by a specialized organization, with the endorsement of the state examination with a permanent technical supervision of construction, manufacturer of structures designs being a specialized factory.

The regulatory snow load wasn't exceeded during the operation period (according to the Prokopyevsk meteorological station). Dynamic effects, including those of seismic character were not observed either.

However, the deformation of bearing girders, the scheme of which is shown in Fig. 9, the destruction of four chord elements, without the roof collapse (Fig. $10-11$, the feature of which is brittle fracture of elements 6-7 (see Fig. 9) of four girders have occurred.

Fig. 9: Geometrical scheme of fractured girder

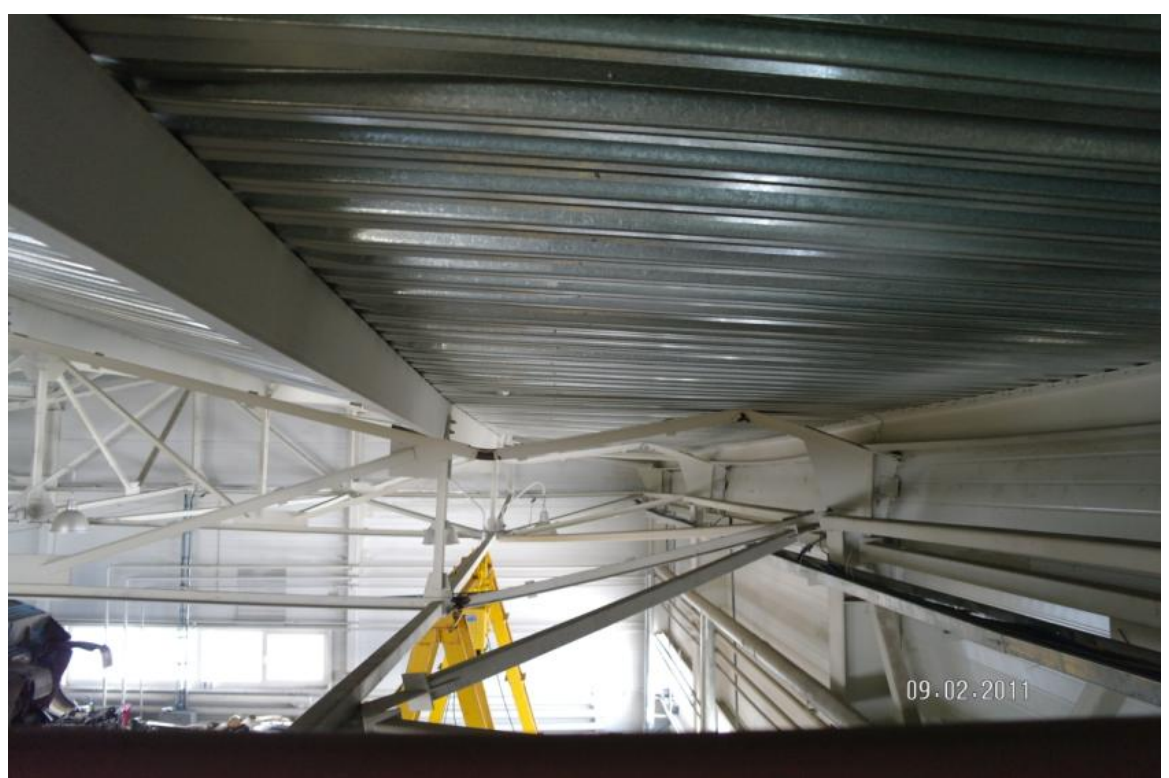

Fig. 10: Girder collapse character 


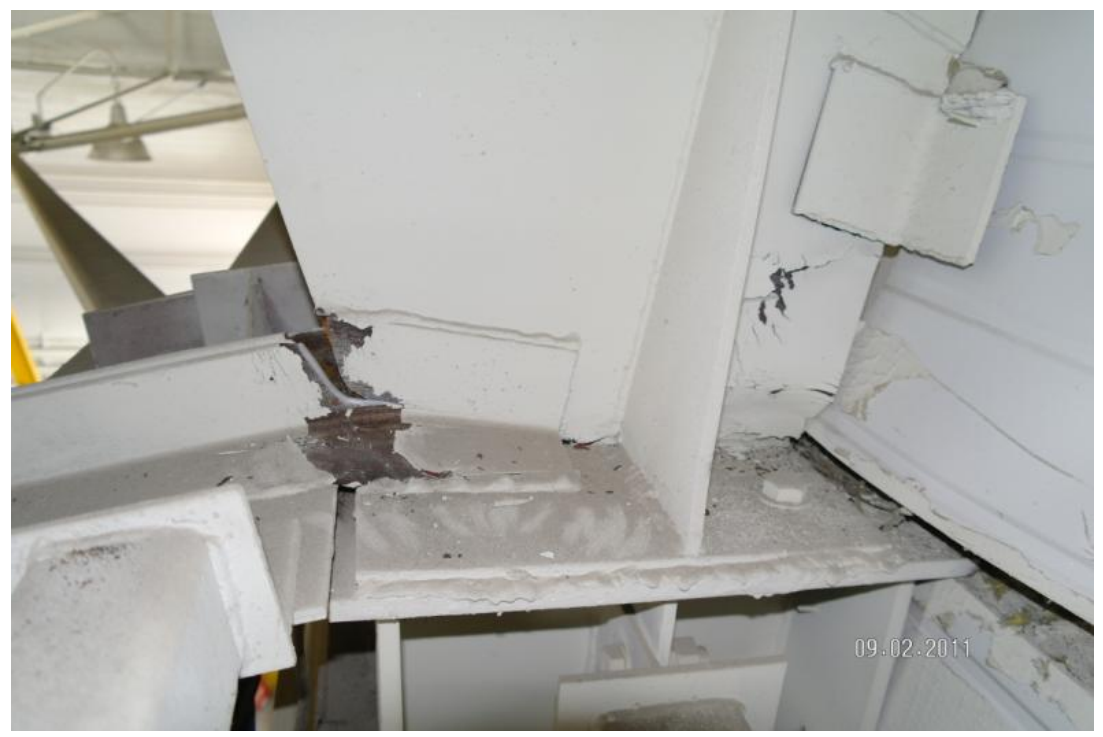

Fig. 11: Brittle fracture of lower chord

Due to the uniqueness of the fracture, as well as to exclude other causes of the structure fractures, a thorough inspection was made. The survey resulted in identification of the nearly two dozens of defects according to Standardized Regulations 13-102-2003 "Rules of surveying the bearing structures of buildings and facilities," but all marked defects were not the causes of the brittle fracture of the lower chord.

Despite the sole cause of the dynamic effects - bifurcation of structure elements, a thorough examination and measurements were performed to exclude other causes of structural collapse, as well as to develop the most optimal method of structure enforcement.

This example clearly shows the danger of non-use of catastrophe theory in FEM analysis of bearing structures of buildings.

\section{Conclusion}

The analysis conducted and the previously mentioned test problems [1] demonstrate that the FEM analysis, solving problems in a static setting is not applicable under bifurcation.

The task of taking into consideration the bifurcation of joints of rods is not just relevant, but critical. Using catastrophe theory applied to the FEM analysis of limit state of bearing structures of mining engineering buildings and facilities will provide, in our view, further development of science (at least - complete it with the real examples of the general theory of bifurcations $^{[4]}$ ) and increase the safety of mining industry buildings and facilities.

\section{References}

[1] Nazarov D.I. Some features o geometrically nonlinear problems // Automation and computerization in construction: collection of research papers of I International scientific conference. - Tula: Tula State University. 2000. - P. 96-99.

[2] Nazarov D.I. About "fidelity" of structural analysis by means of finite element method // CAD systems and graphics. - 2000. - № 7. - P. 53-59.

[3] Nazarov D.I. Catastrophe theory in the problems of condition analysis of mining engineering buildings and facilities // Bulletin of Kuzbass State Technical University - № 2. - 2010 - P. 80-81.

[4] Seydel Rüdiger. Practical bifurcation and stability analysis / Berlin: Springer, 2010. 